OPEN ACCESS

Journal of

Intelligence

ISSN 2079-3200

www.mdpi.com/journal/jintelligence

Comment

\title{
A New Era of Intelligence Research
}

\author{
Andrew R. A. Conway \\ Department of Psychology, Princeton University, Princeton, NJ, 08540 USA; \\ E-Mail: aconway@princeton.edu
}

Received: 18 February 2014; in revised form: 10 March 2014 / Accepted: 24 March 2014 /

Published: 8 April 2014

\begin{abstract}
A consensus definition of intelligence remains elusive but there are many reasons to believe that the field of intelligence is entering a new era of significant progress. The convergence of recent advances in psychometrics, cognitive psychology, and neuroscience has set the stage for the development of stronger theories and more sophisticated models. The establishment of a new open access journal as an outlet for new intelligence research is evidence that the new era has begun.
\end{abstract}

Keywords: intelligence; latent variable models; neuroscience; open access

The first issue of the Journal of Intelligence featured two invited commentaries on the state of intelligence research. The authors were asked to comment on the most important outstanding questions and promising new directions in the field. In essence, the authors were asked by Editor Paul De Boeck to help launch the journal by starting a conversation [1]. My task here is to continue that conversation, to comment on the initial articles, and to provide my own perspective on the field.

The two commentary articles are quite different yet both achieve the goals set by the Editor. According to both articles, the fundamental question, and perhaps problem, is how to define intelligence. I found two comments by Hunt and Jaeggi helpful. First, "word definitions are changed by usage, rather than by dictate, so we do not think that an elegant linguistic solution is likely. The term intelligence, as used in this journal and other similar ones, embodies individual differences in its definition" [2]. Second, "a new definition of intelligence ought to expand the concept beyond the traits traditionally included on tests of cognition, but retain the restriction that the traits involved are cognitive ones" [2].

The commentaries differ a bit with respect to their thoughts on promising new directions. One common theme centers on the idea that intelligence is more malleable and the brain is more 
plastic than most of us thought just a few decades ago. Research on the effect of mindset and performance feedback on intelligence, as well as cognitive training and its effect on intelligence are motivated by this "malleability hypothesis". When investigating the extent to which intelligence is malleable it is important to make the distinction between "intelligence as effective cognitive performance and intelligence as one's relative standing on a set of cognitive traits" [3]. The effects of mindset and training on performance are clear but their effects on relative standing are mixed [4]. Studies on relative standing are complicated by the fact that important individual differences may be at play, for instance, baseline performance may be correlated (positively or negatively) with growth, or growth may be linear for some but not for others, and the long-term effects may be variable and dependent upon previous differences related to baseline and growth. Much more research is needed to address these questions. Finally, this work raises a somewhat existential question: if training works for everyone, and in the same manner, then doesn't it follow that training has no effect on relative standing? Questions like these about relative standing are better addressed by developmental psychologists working from the perspective of models of childhood intelligence and neural development.

In my opinion, the first issue of the journal has set the stage for a new era of intelligence research. Time will tell, but there is reason to believe that we are embarking on an era that will eventually be considered a time of historical importance for intelligence. Of course it is impossible to accurately predict the future impact of current work but the last decade has been prolific to say the least. A discussion of recent advances is beyond the scope of this brief report, and as mentioned, the most promising new lines of research are nicely summarized in the first issue. The reason for excitement, to me at least, is that so many new findings have coincided with two other developments that will push the science forward: (1) new methods in neuroscience; and (2) open access publishing.

The field of neuroscience has now reached a stage where large sample neuroimaging studies are being conducted, providing insight into neural measurement issues. Now, for the first time, latent variable models of intelligence will be able to integrate behavioral and neural data. This paves the way for testing theories about inter-individual differences in terms of intra-individual psychological processes and their underlying neural mechanisms and allows for the integration of psychometrics, cognitive psychology, and neuroscience.

Finally, the Journal of Intelligence is open access. As defined by the 2002 Budapest Open Access Initiative, "By 'open access' to this literature, we mean its free availability on the public internet, permitting any users to read, download, copy, distribute, print, search, or link to the full texts of these articles" [5]. Free and open access, in the context of intelligence research, creates an incredibly powerful feedback loop; each issue of the journal will provide new insights on the nature of intelligence, and these insights will be widely shared, thus advancing and promoting intelligence like never before. 


\section{References}

1. De Boeck, P. Intelligence, where to look, where to go? J. Intell. 2013, 1, 5-24.

2. Hunt, E.; Jaeggi, S.M. Challenges for research on intelligence. J. Intell. 2013, 1, 41.

3. Hunt, E.; Jaeggi, S.M. Challenges for research on intelligence. J. Intell. 2013, 1, 44.

4. Shipstead, Z.; Redick, T.S.; Engle, R.W. Is working memory training effective? Psychol. Bull. 2012, 4, 628-654.

5. Budapest Open Access Initiative. Available online:

http://www.budapestopenaccessinitiative.org/read (accessed on 10 March 2014)

(C) 2014 by the authors; licensee MDPI, Basel, Switzerland. This article is an open access article distributed under the terms and conditions of the Creative Commons Attribution license (http://creativecommons.org/licenses/by/3.0/). 